\title{
LOS EFECTOS EN LOS DERECHOS HUMANOS DE LAS SECESIONES DE ESTADOS Y ENTIDADES NO ACEPTADAS POR LA COMUNIDAD INTERNACIONAL
}

\author{
Ana Gemma López Martín \\ Catedrática de Derecho Internacional Público y RRII. \\ Dpto. Derecho Internacional, Eclesiástico y Filosofía del Derecho \\ Facultad de Derecho de la Universidad Complutense de Madrid \\ anagema@der.ucm.es \\ José Antonio Perea UnCeTA \\ Profesor Contratado Doctor de Derecho Internacional Público y RRII. \\ Dpto. Derecho Internacional, Eclesiástico y Filosofía del Derecho \\ Facultad de Derecho de la Universidad Complutense de Madrid \\ japereau@der.ucm.es
}

\section{RESUMEN}

El proyecto secesionista de una parte de la sociedad de Cataluña exige reflexionar sobre cómo se han comportado y cómo se comportan actualmente tanto los Estados que se han creado mediante secesión como las entidades de facto, no reconocidas por la comunidad internacional, en lo que respecta a los derechos bumanos de las minorías resultantes en ellos. En países como Estonia y Letonia se aprecian situaciones anómalas en relación con la denegación de la nacionalidad a la población de origen ruso por su desconocimiento del idioma nacional, en Eritrea se impidió el regreso de los eritreos que vivian en Etiopía por desconfianza con su movilización a favor del nuevo Estado, en Macedonia se manipularon los distritos electorales para minimizar la representación parlamentaria de los albaneses, etc. Al no haber una norma internacional general que asegure que los nuevos Estados siguen obligados por los tratados en materia de derechos humanos del Estado matriz, el único recurso para asegurar la vigencia de los mismos es la actuación de los organismos internacionales supervisores. En el caso de los Estados, mediante la formulación de una «doctrina de los derechos bumanos adquiridos» que impide el vacío legal para el Tribunal Europeo de Derechos Humanos o el Comité de Derechos Humanos de la ONU, y en el caso de las entidades de facto, como Nagorno-Karabaj, Transnistria o la República Turca del Norte de Chipre, con un juego de reglas que impiden ese vacio de responsabilidad en virtud del cual se presume la del Estado titular de la soberanía, presunción que se destruye — sin perjuicio de mantener «obligaciones internacionales positivas»- si una parte del territorio es ocupada militarmente por otro Estado, siendo este el responsable, y sin perjuicio de que, incluso habiéndolo, también pueda exigirse a una autoridad local insurgente si no actúa bajo el control efectivo de esa potencia ocupante. Esta práctica revela una situación jurídica ciertamente peligrosa para la vigencia de los derechos humanos de las minorías resul- 
tantes en Estados y entidades secesionadas, situación que debe ser corregida, especialmente en el ámbito regional europeo, para evitar que se repita en eventuales procesos secesionistas, como el que podría acontecer en Cataluña.

Palabras clave: Derecho internacional público, minorías nacionales, secesión, derechos humanos, Consejo de Europa, sucesión de Estados, Cataluña.

\section{ABSTRACT}

The secession project of part of Catalan society involves reflecting on how they have behaved and currently behave those states created by secession as well as the de facto ones, which have not been internationally acknowledged, with regards to the buman rights of the minorities being created in them. In countries such as Estonia and Latvia we can find rare cases where a Russian nationality is unacceptable for those subjects with a lack of knowledge of the local language; Eritreans living in Ethiopia were banned in Eritrea on their way back under suspicion of support of the new state. In Macedonia constituencies were manipulated not to let Albanians win the power. This is just to name but a few examples. Since there is no general international law which guarantees the new states' compliance with treaties regarding buman rights created by the source state the only resource to assure the validity of such treaties is international surveillance bodies taking action. As for such states with a wording on the lines of «a tenet of acquired buman rights» which tends to avoid legal void, it should be the European Court of human Rights or the Human Right Committee of the UN. Regarding de facto entities such as NagornoKarabaj, Transnistria or the Turkish Republic of Northern Cyprus, a play on rules would avoid such responsibility void and will presume that of the State which owns sovereignty. Having said so such presumption disappears (positive international duties permitting) if one part of the territory is taken by the army of another state, in which case the latter becomes the responsible one. Upcoming authorities could also be claimed responsible if they do not act guided by the other party's effective control. Such practice proves to be an extremely delicate legal case for the validity of the buman rights of the upcoming minorities in both secession states and entities and such case must be corrected, particularly within a European regional frame in order to prevent it from happening again eventually in parallel secession processes such as the one happening in Catalonia.

Keywords: public International Laws, national minorities, secession, Human Rights, European Council, Succession of States, Catalonia.

\section{ZUSSAMENFASSUNG}

Das Abspaltungsprojekt eines Teils der katalanischen Gesellschaft macht es erforderlich, darüber zu reflektieren, wie sich sowobl die geschaffenen Staaten als auch die de facto entstandenen Gemeinwesen, die nicht von der internationalen Staatengemeinschaft anerkannt werden, in Bezug auf die Menschenrechte und die Rechte ibrer enthaltenen Minderbeiten verbalten bzw. verbalten werden. In Ländern wie Estland und Litauen sind Unregelmäßigkeiten dabingebend zu beobachten, dass der russischstämmigen Bevölkerung die Nationalität verweigert wird, da sie nicht die Landessprache sprechen; in Eritrea wurde denjenigen Eritreern die Rückkebr verweigert, die in Äthiopien Ibren Wobnsitz batten, aus Misstrauen wegen ibres Einsatzes für den neuen Staat; In Mazedonien wurden die Wablbezirke verändert, um die Vertretung der Albaner im Parlament zu reduzieren; usw. Da 
es keine allgemeinen internationalen Normen gibt, die sicherstellen, dass die neugebildeten Staaten bei der Einhaltung der Menschenrechte an die ratifizierten Verträge Ibrer Ausgangsstaaten gebunden sind, hängt alles vom Eingreifen der internationalen Überwachungsorganisationen ab. Im Fall der Staaten mittels einer «Lebre von den erworbenen Menschenrechten», die das Rechtsvakuum verbindert. Zuständig wäre bei Staaten der EGMR, der Europäische Gerichtshof für Menschenrechte der UNO. Im Falle der «de facto» Gemeinwesen, wie Bergkarabach, Transnistrien oder die Türkische Republik Nordzypern erfolgt die Normbindung durch ein paar Spielregeln, die das Verantwortlichkeitsvakuum verhindern. Hierzu wird die Souveränität des herrschenden Staats anerkannt, jedoch —ohne staatliche internationale Verpflichtungen-bis das Gebiet wiederum von einem neuen Staat besetzt wird und dieser nun in der Verantwortung stebt. Diese Verantwortlichkeit, kann auch gegenüber einer Aufstandsbewegung innerbalb dieses besetzten Gebiets geltend gemacht werden, wenn diese nicht unter der effektiven Kontrolle der Gebietsbesetzer stebt. Diese Praxis offenbart gewiss eine gefährliche juristische Situation für die Gültigkeit der Menschenrechte der resultierenden Minderbeiten in den abgespaltenen Staaten oder Gemeinwesen. Diese Situation sollte korrigiert werden, besonders im Bereich der europäischen Regionen, um zu verbindern, dass diese Situation sich bei anderen Abspaltungsprozessen wiederbolt, so wie es in Katalonien der Fall sein könnte.

Schlüsselwörter: Internationales öffentliches Recht, nationale Minderheiten, Sezession, Menschenrechte, Europarat, Staatennachfolge, Katalonien.

SUMARIO: I. INTRODUCCIÓN.-II. LAS AMENAZAS A LOS DERECHOS FUNDAMENTALES DE LAS MINORÍAS RESULTANTES EN ESTADOS SECESIONADOS.--III. LA PROBLEMÁTICA DE LA SUCESIÓN DE TRATADOS SOBRE DERECHOS HUMANOS EN LOS SUPUESTOS DE SECESIÓN.-IV. LA ACTUACIÓN INSTITUCIONAL EN RELACIÓN CON LAS VIOLACIONES DE LOS DERECHOS HUMANOS EN LAS ENTIDADES DE FACTO.-V. CONSIDERACIONES FINALES CON LA VISTA PUESTA EN CATALUÑA.-VI. BIBLIOGRAFÍA.

\section{INTRODUCCIÓN}

En los últimos años se ha instalado en los debates políticos y académicos la diversa problemática que plantea el intento de secesión promovido por una parte de los partidos políticos de Cataluña y, de alguna forma, casi la mitad de sus habitantes. El secesionismo, como última expresión del nacionalismo, aunque es un tema recurrente en Europa desde principios de los años noventa, reside, sin embargo, en el ADN continental desde hace varios siglos, ya sea por las ansias de libertad de los pueblos sojuzgados por los Imperios otomano, austro-húngaro o ruso, ya sea simplemente por el localismo exacerbado de las diferentes comunidades que integran los diferentes Estados multiétnicos europeos. Estas fuerzas centrífugas tuvieron un senti- 
do innegable en los tiempos y en los regímenes en los que se discriminaba a las minorías por razón de su diferencia religiosa, lingüística, étnica, racial, socioeconómica o de cualquier otra índole, pero hoy en día resultan ciertamente contradictorias con el esfuerzo de integración del proyecto político de la Unión Europa. Por ello, si resulta discutible que donde hubo opresión social y política se hayan pretendido construir fundamentos jurídicos inexistentes en el estado actual del Derecho internacional, parece sin duda más chocante todavía defender -incluso en ausencia de esa represión de los derechos fundamentales - supuestas instituciones jurídicas que amparen un secesionismo basado exclusivamente en la voluntad de una parte de la población de un territorio del Estado.

En el ordenamiento jurídico internacional el derecho de libre determinación de los pueblos se restringe por la voluntad de los sujetos internacionales, que son los creadores de las normas que lo integran, a los que están sometidos por la fuerza o en situación de dominio colonial. Los demás pueblos, esto es, los denominados «minorías nacionales» $\mathrm{y}$ «pueblos indígenas», con elementos comunes, pero con características que los distinguen entre sí y también respecto de las colonias, en el Derecho internacional vigente tienen reconocidos principalmente sus derechos a la no discriminación y al ejercicio de su diferenciación en su cultura, su lengua, su religión, etcétera.

No obstante esta exclusión de los supuestos no coloniales del régimen jurídico de libre determinación de los pueblos, lo cierto es que la historia cuenta con un número relevante de casos en los que estas minorías nacionales (étnicas, lingüísticas o religiosas) han pretendido o han conseguido secesionarse de sus Estados, eso sí, no siempre de forma plena — es decir, constituyendo auténticos Estados-y en buena parte de los casos sin contar con la aceptación de la comunidad internacional. De los imperios citados anteriormente se han secesionado, es decir, se han separado sin su consentimiento, Estados que lo son realmente y que además han sido reconocidos como tales (como Grecia en el siglo XIX o Croacia en el Xx), ya sea por la fuerza de las armas, por rebelión social o por la presión o coacción de otros Estados, ya sea por la fuerza de los hechos o por tratados más o menos impuestos tras conflictos armados. Pero, además, también han surgido entidades territoriales con pretensiones de adquirir la condición de Estados y que, sin embargo, no lo son plenamente [como Kosovo, Transnistria, Osetia del Sur o la República Turca del Norte de Chipre (en adelante, RTNC)] o que, aparentándolo, no han sido aceptadas como tales por la comunidad internacional (como Somalilandia). Otras entidades se han mantenido durante un tiempo y han desaparecido por la oposición arma- 
da de los Estados en los que estaban integradas (como Biafra, 1967-1970; Chechenia, 1992-2000, o la isla de Anjouán, 1997-2008).

Desde una perspectiva iusinternacionalista, ambos fenómenos tienen problemas propios de nuestro estudio, como su eventual ubicación en el marco de la libre determinación de los pueblos y la legalidad en su proceso de creación, cuestiones ambas especialmente ligadas a la subjetividad internacional y que han sido objeto de análisis en la doctrina desde diferentes perspectivas y con diferentes soluciones ${ }^{1}$. Hay otras cuestiones, sin embargo, que afectan directamente a las poblaciones de esos territorios y resultan particularmente interesantes, aunque escasamente abordadas por la doctrina; nos referimos a cómo influye el cambio en la titularidad de la soberanía en el supuesto particular de la secesión a los derechos fundamentales de la población. Dependiendo de la aceptación internacional y de su plena efectividad, entre otras circunstancias, serán también más o menos viables y eficaces los mecanismos internacionales de supervisión y reparación. Así, las entidades no reconocidas internacionalmente no disponen generalmente de instrumentos habituales en las relaciones internacionales derivados de la participación en determinados tratados u organizaciones internacionales.

Especialmente grave es el hecho de que en buena parte de las últimas secesiones tanto de facto — rechazadas por la comunidad internacionalcomo concluidas y aceptadas — con pleno acceso a la estatalidad — se han producido graves deficiencias en materia de derechos humanos y, en particular, respecto de las nuevas minorías resultantes. Secesiones aceptadas como las de Estonia, Macedonia o Eritrea, y otras contestadas como las de Transnistria, RTNC o Kosovo, han desvelado un patrón cada vez más común de resistencia, cuando no de beligerancia oficial, contra el ejercicio de su diferenciación.

La práctica internacional muestra que hasta que se produce la aceptación general de la comunidad internacional puede haber una situación anómala en relación con los derechos fundamentales de la población de ese territorio secesionado, ya sea porque al no participar en los mecanis-

${ }^{1}$ Vid. entre otros, en la doctrina extranjera, A. CASSESE, Self-Determination of Peoples: A Legal Reppraisal, New York, Cambridge University Press, 1995, y J. CRAwFord, The Creation of States in International Law, New York, Oxford University Press, 1997, y en la española, J. A. Perea Unceta, El Derecho internacional de secesión, Madrid, Facultad de Derecho de la UCM, 2008; A. MARTínez JimÉNEZ, El derecho de autodeterminación de los pueblos en el siglo XXI, Pamplona, Aranzadi, 2015, y, centrándose en la cuestión catalana, X. PONS RAFOLS, Cataluña: derecho a decidir y Derecho internacional, Madrid, Reus, 2015. 
mos internacionales de supervisión peligra la efectiva protección de los mismos, ya sea porque - incluso en casos de aceptación internacionalla propia dinámica de su creación conlleve una suspicacia, y en ocasiones franca discriminación subsiguiente, de la parte de la población que no se movilizó ni se adhiere al nacionalismo impulsor de esa secesión.

Nuestro país vive en tensión por el intento secesionista de una parte de los partidos políticos y de la sociedad catalana. La actuación llevada a cabo por el Parlamento de la Comunidad Autónoma de Cataluña en los últimos meses de 2017 debe hacernos reflexionar sobre esta práctica de los Estados y entidades secesionistas, aunque solo sea para prevenir situaciones como las que se han padecido o se sufren todavía en estos escenarios.

Puesto que algunos temas han sido tratados de forma extensa en nuestra literatura científica, como los derivados de una consiguiente e inevitable exclusión de la Unión Europea (en adelante, UE) si se consumase la secesión $^{2}$, nos centraremos en un análisis, meramente ejemplar, de la práctica de Estados y entidades secesionadas, y de las organizaciones internacionales europeas supervisoras de la vigencia de los derechos humanos. Para ello expondremos, en primer lugar, algunos ejemplos tanto de situaciones discriminatorias o simplemente poco equitativas con las minorías resultantes que se han producido en países como Estonia, Letonia, Lituania, Eritrea, Macedonia, Croacia, Albania o Bosnia-Herzegovina, como de la respuesta a estas situaciones, ilícitas o anómalas, de organizaciones internacionales competentes en materia de derechos humanos como la Organización para la Seguridad y la Cooperación en Europa (en adelante, OSCE), el Consejo de Europa y las Naciones Unidas. En segundo lugar, plantearemos el problema que implica la ausencia de una norma jurídica general que asegure la protección de los derechos que venían disfrutando la población en ese periodo de acceso a la independencia de los nuevos Estados surgidos por secesión, así como

\footnotetext{
${ }^{2}$ Vid., entre otros, M. Medina Ortega, «Los ciudadanos europeos y la secesión de territorios en la Unión Europea», Revista de Derecho de la Unión Europea, núm. 25 (2013), pp. 69-86; T. FreiXes SANJuÁn, «Secesión de Estados e integración en la Unión Europea. A propósito del debate sobre la permanencia en la Unión de Escocia y Cataluña como Estados segregados del Reino Unido y España», Revista Jurídica de Catalunya, núm. 2 (2014), pp. 297-329; P. GARCíA ANDRADE, «La ciudadanía europea y la sucesión de Estados: a vueltas con las implicaciones de una separación territorial en el seno de la UE», Revista de Derecho Comunitario Europeo, núm. 49 (2014), pp. 997-1025; J. RidAo MarTín y A. GonZÁlez BonDÍA, «La Unión Europea ante la eventual creación de nuevos Estados surgidos de la secesión de Estados miembros», Revista de Derecho de la Unión Europea, núm. 28 (2014), pp. 363 390, e Y. Radoslavov YoRDANOV, «La secesión de territorios en un Estado miembro de la Unión Europea y sus consecuencias en relación con las minorías resultantes», Anuario Hispano-Luso-Americano de Derecho Internacional, vol. 23 (2017), pp. 385-422.
} 
la solución práctica adoptada por las organizaciones internacionales supervisoras. A continuación, pondremos algunos ejemplos de cómo estas organizaciones, especialmente el Tribunal Europeo de Derechos Humanos (en adelante, TEDH), están asegurando en la práctica la vigencia de los derechos fundamentales en las entidades de facto. Para concluir con unas consideraciones finales con la vista puesta en lo que pueda suceder y haya que evitar en una hipotética secesión de Cataluña derivadas de este panorama ejemplar y de las propuestas legislativas secesionistas de su Parlamento.

\section{LAS AMENAZAS A LOS DERECHOS FUNDAMENTALES DE LAS MINORÍAS RESULTANTES EN ESTADOS SECESIONADOS}

Lo que mueve a los grupos humanos a separarse de su Estado es siempre - pues es intrínseco al propio concepto de minoría nacional- ${ }^{3}$ la defensa de la identidad propia, y cuanto más difícil, larga o cruenta es la lucha por la independencia, mayor es posteriormente, una vez conseguida, la exclusión social de las comunidades minoritarias de ese nuevo Estado. Aunque estos procesos secesionistas pueden tener en algunos casos fundamentos políticos muy sólidos - por incumplimiento de los acuerdos constitucionales de convivencia, como en el caso de Eritrea (independiente en 1993 de Etiopía), o por discriminación grave e incluso genocida de su población, como en el caso de Sudán del Sur (independiente en 2011 de Sudán)_, no hay un auténtico fundamento jurídico internacional en el que basar la pretensión de independencia, como se ha manifestado en la introducción de este estudio, por mucho que la Asamblea General aprobase en 1970 una resolución, de valor recomendatorio, como se sabe, en la que declarase la denominada «cláusula democrática», reinterpretada posteriormente por una parte de la doctrina y de los gobiernos en la conocida como «doctrina de la secesión-remedio» ${ }^{4}$.

3 Conforme a la Recomendación 1201 (1993), de 1 de febrero, de la Asamblea Parlamentaria del Consejo de Europa, las características definitorias de las minorías nacionales son: la población que la integra residen y son ciudadanos del Estado del que forman parte; han mantenido vínculos con este durante un largo tiempo; tienen diferencias étnicas, culturales, religiosas o lingüísticas con otras poblaciones del Estado; son suficientemente representativas en un territorio determinado del mismo en el que están implantadas; son una parte no mayoritaria de la población estatal, y tienen una voluntad de preservar su identidad común.

${ }^{4}$ Sobre esta doctrina, y en general sobre la previsión contenida en el párrafo séptimo de la Resolución 2625 (XXV), de 24 de octubre de 1970, de la Asamblea General de las Nacio- 
Esa diferenciación intrínseca - elemento objetivo del concepto de pueblo- cuando va acompañada de una situación de discriminación étnica o religiosa, o de dominio por la fuerza, o de agravio socioeconómico, o de cualquier otra circunstancia similar, y especialmente del sentimiento creado más o menos artificial e interesadamente de que existen tales circunstancias, genera un sentimiento nacionalista que, una vez producida la secesión (de facto o aceptada internacionalmente), conduce generalmente a regímenes que intentan excluir de la sociedad —o al menos de sus ámbitos de gestión - a los que no comparten la identidad (elemento objetivo) o la movilización nacional (elemento subjetivo del pueblo) de sus promotores $^{5}$. Aunque se alegue que en determinadas situaciones es necesario para conseguir la independencia —o para mantenerla—, sobre todo cuando en el territorio secesionado permanece una amplia población no movilizada nacionalmente o con unas características diferentes, especialmente si es afín al «Estado matriz», lo cierto es que estos argumentos políticos no pueden excusar un incumplimiento de los estándares internacionales, universales y regionales, de protección de los derechos humanos.

El objeto de este estudio no es exponer el régimen jurídico internacional de protección de los derechos humanos de las minorías nacionales ${ }^{6}$, sino apuntar algunos de los problemas que se plantean en este contexto cuando la generación de estas minorías es consecuencia de un proceso de secesión, esto es, como se ha dicho inicialmente, de una separación de una parte de la población y el territorio de un Estado (que hemos llamado «matriz») sin su consentimiento. Se trata, por tanto, de un supuesto concreto de minoría nacional, que es el resultante de ese proceso secesionista. Sin embargo, a su vez, puede manifestarse en diferentes situaciones y con circunstancias diversas: puede producirse o bien en Estados efectivamente secesionados y aceptados como tales por la comunidad internacional (una

nes Unidas, vid., entre otros, Th. D. MusGrave, Self-Determination and National Minorities, New York, Oxford University Press, 2000; A. TANCREDI, La secesione nel diritto internationale, Padova, Cedam, 2006, y A. G. López Martín y J. A. Perea Unceta, Creación de Estados, secesión y reconocimiento, Valencia, Tirant Lo Blanch, 2018, pp. 161 y ss.

5 Sobre las relaciones entre defensa de la identidad y exclusión política y social del que no la comparte, ya sea respecto de una minoría tradicional o de un colectivo de inmigrantes recientes, vid. E. Ruiz VieYTEZ, Minorías, inmigración y democracia en Europa. Una lectura multicultural de los derechos bumanos, Valencia, Tirant Lo Blanch, 2006, en general, y en especial pp. 107 y ss., y 445-477.

${ }^{6}$ Sobre esta cuestión general vid., entre otros, C. DíAz BARRADO, La protección de las minorías nacionales en el Consejo de Europa, Madrid, Edisofer, 1999, p. 199; F. MARIÑo MENÉndeZ, La protección internacional de las minorías, Madrid, Ministerio de Asuntos Sociales, 2001, y B. ARP, Las minorías nacionales y su protección en Europa, Madrid, CEC, 2008. 
secesión plena, como Bangladesh en 1971 o Estonia, Letonia y Lituania en 1991) o bien en entidades en proceso de secesión no completadas (Kosovo desde 1999) o contestadas e incluso frustradas (Tamil Ealan entre 1990 y 2009) o no reconocidas internacionalmente (Somaliland desde 1991), o en secesiones tuteladas por otros Estados que no han sido aceptadas por la comunidad internacional y que, en realidad, han dado lugar a entidades con apariencia de estatalidad pero que no cuentan con su principal elemento, que es la independencia de otros Estados, y que por la forma de su creación — vulnerando los principios fundamentales del ordenamiento jurídico internacional, como el respeto a la integridad territorial o la prohibición del uso de la fuerza - no han sido aceptados por la generalidad de los Estados (RTNC desde 1983 o Transnistria desde 1991).

En lo que respecta a los problemas específicos de los Estados surgidos por secesión impulsada por minorías nacionales de los anteriores Estados matrices, hay que destacar que manifiestan en algunos casos notorias carencias en materia de protección de los derechos humanos de las nuevas minorías resultantes en sus propios territorios. Esta situación deficitaria es evidente cuando su creación ha sido consecuencia de un conflicto armado interno de naturaleza étnica o religiosa, como es el caso - al menos en los primeros años- de Croacia, e incluso cuando se ha producido después de una larga etapa de dominio del territorio por una potencia anexionista, como es el caso - incluso actualmente respecto de los ruso-hablantes- de Letonia. La mayoría étnica, religiosa o lingüística del nuevo Estado no solo no es proclive a reconocer a sus minorías el mismo derecho de secesión que impulsó su creación —-como resultó evidente respecto de la comunidad serbia de Croacia (República de Krajina)_, sino que suele considerar a estas como ajenas a su movimiento nacionalista (minoría polaca de Lituania) o incluso como enemigas del mismo y un peligro para la viabilidad y la seguridad del nuevo Estado si coincide dicha minoría con la mayoría demográfica del Estado matriz (minoría rusa de Estonia). Por ello no es de extrañar que una parte de estos nuevos Estados sea renuente a participar en determinados tratados sobre derechos humanos.

Así, Estonia y Letonia no son parte en el Protocolo Facultativo de 2008 del Pacto Internacional de Derechos Económicos, Sociales y Culturales de 1966, que es el que permite actuar al Comité de Derechos Económicos, Sociales y Culturales (en adelante, DESC); tampoco en el procedimiento del art. 8 (instaurado en 1992) del Convenio para la Eliminación de todas las Formas de Discriminación Racial de 1966, que faculta al Comité contra la Discriminación Racial, y tampoco en el Protocolo de 1995 de la Carta 
Social Europea de 1961 (ratificada por fin en 2000 y 2013, respectivamente), que otorga poder al Comité para investigar y emitir recomendaciones ${ }^{7}$. Del mismo modo, Estonia, Letonia, Lituania, Macedonia o Albania no son parte en la Carta Europea de Lenguas Regionales o Minoritarias de 1992, y aunque todos ellos son parte en el Convenio Marco de Minorías de 1995, Letonia mantiene una reserva en lo que respecta al derecho de las minorías a usar su lengua en los procedimientos administrativos. En la misma línea, Estonia no es parte ni en el Convenio sobre el Estatuto de los Apátridas de 1954, ni en el Convenio para la Reducción de la Apatridia de 1961 [ambos de la Organización de las Naciones Unidas (en adelante, ONU)], ni en la Convención Europea sobre la Nacionalidad de 1997, ni en el Convenio sobre Prevención de los Casos de Apatridia con relación a la sucesión de Estados del Consejo de Europa de 2006. En el Convenio de 1954 no son parte tampoco ni Eritrea ni Sudán del Sur, y en el Convenio Europeo de 1997 no participan Albania, Bosnia, Letonia, Lituania, Serbia y Eslovenia; tampoco en el de 2006, que solo tiene siete ratificaciones, entre ellas la de Montenegro.

$\mathrm{El}$ acceso a la nacionalidad se obstaculiza o se veta en alguno de estos países para evitar la integración laboral de personas afines al Estado matriz y su participación en la vida política. La forma habitual de hacerlo es vinculando la nacionalidad con el conocimiento del idioma identitario. De esta manera, nuevos Estados como Estonia y Letonia adquieren la condición de auténticas «democracias étnicas», esto es, países en los que se distingue entre nacionales de origen étnico y nacionales que no lo son ${ }^{8}$ pero conocen el idioma mayoritario e identificado con el territorio, y entre dichos nacionales y otros que no lo son porque, aunque residentes e incluso nacidos en el territorio, sin embargo, no conocen el idioma nacional ${ }^{9}$. Puesto que uno de los requisitos para la constatación de una minoría

\footnotetext{
7 Tampoco otros creados mediante secesión, como Lituania, Albania, Bosnia, Montenegro, Serbia y Macedonia.

${ }^{8}$ En Estonia la adscripción étnica es oficial y consta en la documentación personal: certificación de nacimiento y pasaporte.

9 Como señala P. Järve, «Ethnic Democracy and Estonia: Application of Smooha's Model», European Centre for Minority Issues Working Paper, núm. 7 (2000), el fundamento legal de la democracia étnica en Estonia se encuentra en el preámbulo de su Constitución cuando distingue entre «nación estonia» (eesti rabvus) y «pueblo estonio» (eesti rabvas), incluyendo en este a todos los ciudadanos y en aquel solo a los de origen étnico estonio, y en una legislación que otorga la posibilidad de participar en los partidos políticos y en las elecciones no municipales exclusivamente a los que forman parte de aquella o han demostrado su integración en la misma. Sobre esta cuestión vid. también A. AASLAND, «Citizenship Status and Social Exclusion in Estonia and Latvia», Journal of Baltic Studies, vol. 33, núm. 1 (2007), pp. 57-77; G. SмIтH, «The Ethnic Democracy Thesis and the Citizenship Question
} 
nacional es que se trate de una comunidad asentada en el territorio durante una largo tiempo - en las legislaciones de Europa oriental, generalmente superior a un centenar de años- ${ }^{10}$ y la presencia rusa en las repúblicas bálticas se desarrolla sobre todo a partir de la ocupación soviética en 1940, los ruso-hablantes o «rusos bálticos» tienen un estatus equiparable solo al de inmigrantes residentes, por mucho que hayan nacido en el territorio, sus familias lleven varias generaciones en él y no manifiesten ningún interés en abandonarlo.

En Letonia, con la aprobación en 1991 de la Ley de Nacionalidad, se reinstauró la nacionalidad a los individuos que en 1940 eran ciudadanos de Letonia y a sus descendientes, quedando los inmigrantes soviéticos y sus descendientes nacidos en Letonia excluidos de la nacionalidad (en 1991, el 47 por 100 de la población, con una minoría rusa del 34 por 100). Tras las presiones del Consejo de Europa, en la Ley de Ciudadanía de 1994 se permitió la naturalización a los residentes permanentes que acreditasen haber estudiado en un colegio que impartiera clases en letón, así como a sus hijos; sin embargo, el procedimiento era tan complejo y el examen de idioma y de historia tan difícil que en 1998, a instancias de la OSCE, se suprimió para los mayores de sesenta y cinco años ${ }^{11}$. Esto ha hecho que de sus 1.950.000 habitantes, actualmente 386.000 (19,79 por 100) sean extranjeros y 238.000 (12,20 por 100) tengan pasaporte de Letonia, pero sin disfrutar de su nacionalidad (en lo que se llama Nepilsona paselalien's Passport). Asimismo, no solo no pueden participar en las elecciones, sino que hay más de treinta profesiones privadas o puestos públicos que no pueden desempeñar - como abogados-, pese a las recomendaciones para corregirlo emitidas por la UE, la ONU, el Consejo de Europa y la OSCE ${ }^{12}$.

in Estonia and Latvia», Nationalities Papers, vol. 24, núm. 2 (2007), pp. 199-216, y D. GALBREATH, «The Politics of European Integration and Minority Rights in Estonia and Latvia», Perspectives on European Politics and Society, vol. 4, núm. 1 (2008), pp. 35-53.

${ }^{10}$ La Ley de Autonomía Cultural para las Minorías Nacionales de 1993 de Estonia no establece un plazo y simplemente reproduce el tenor al respecto de la Resolución 1301 citada de la Asamblea Parlamentaria del Consejo de Europa, pero sí excluye a sus integrantes de la nacionalidad, como la Ley de Croacia de 2002 y la de Polonia de 2005.

${ }^{11}$ Sobre la actuación de la OSCE en Letonia en esta materia vid. J. Dorodnova, «Challenging Ethnic Democracy: Implementation of the Recommendations of the OSCE High Commissioner on National Minorities to Latvia, 1993-2001», CORE Working Paper, núm. 9 (2003).

12 En las observaciones finales sobre el tercer informe periódico de Letonia del Comité de Derechos Humanos de 11 de abril de 2014 se dice (apartado 7) que «siguen preocupando al Comité el estatuto de los residentes que no son ciudadanos y la situación de las minorías lingüísticas. En particular, le preocupan las repercusiones de la política lingüística del Estado en el disfrute de los derechos enunciados en el Pacto, sin discriminación alguna, por 
Una situación similar se produce en Estonia, que en 1991 restablece su Ley sobre Nacionalidad de 1938, de tal modo que es necesario que uno de los padres sea estonio para que el niño lo sea, y aunque en la posterior Ley de Ciudadanía se admiten otras formas de naturalización, todas ellas requieren el conocimiento del estonio. Esta exigencia excluyó de la nacionalidad estonia a un porcentaje importante de la población residente que llevaba viviendo en el país más de cincuenta años, pues en 1991 había un 40,5 por 100 de no estonios (con un 30,3 por 100 de origen ruso). Esta situación se moderó el 1 de enero de 2017 al permitir a los descendientes de progenitores apátridas adquirir automáticamente la nacionalidad estonia al nacer, como consecuencia, como en el caso anterior, de las presiones ejercidas por las organizaciones internacionales europeas. Actualmente, de 1.316 .000 habitantes, 109.000 son extranjeros (8,28 por 100) y 102.000 (7,75 por 100) tiene un «pasaporte gris» (llamado Valismaalaie Pass) similar al letón. También en este país se ha impedido el desempeño de trabajos en el sector privado cuando suponga trato con el público si no se conoce el idioma nacional, tal y como establece la Ley del Idioma Estatal de 1995, que permite su comprobación mediante inspección laboral ${ }^{13}$. Esta discriminación es contraria, en cualquier caso, al Convenio relativo a la discriminación en materia de empleo y ocupación núm. 111 de la Organización Internacional del Trabajo (en adelante, OIT) de 1958, que prohíbe «cualquier distinción, exclusión o preferencia basada en motivos de raza, color, sexo, religión, opinión política $\mathrm{o}$ ascendencia nacional» ${ }^{14}$.

En el contexto electoral tanto este requisito del conocimiento del estonio como la facultad de inspección y verificación en los candidatos electo-

los miembros de las minorías lingüísticas, entre ellos el derecho a elegir y cambiar el propio nombre y el derecho a un recurso efectivo. El Comité también está preocupado por los efectos discriminatorios del requisito de conocimiento del idioma en el empleo y el trabajo de los grupos minoritarios (arts. 2, 26 y 27). El Estado Parte debe reforzar su labor para asegurar el pleno disfrute de los derechos enunciados en el Pacto por los residentes que no son ciudadanos y los miembros de las minorías lingüísticas, y facilitar en mayor medida su integración en la sociedad. Asimismo, debe revisar la Ley del Idioma Oficial del Estado y su aplicación para que toda restricción de los derechos de las personas que no hablan letón sea razonable, proporcionada y no discriminatoria, y adoptar medidas para asegurar el acceso de las personas que no hablan letón a las instituciones públicas y facilitar su comunicación con las autoridades públicas. El Estado Parte debe también estudiar la posibilidad de ofrecer gratuitamente más cursos de idioma letón a los no ciudadanos y los apátridas que deseen solicitar la ciudadanía letona».

${ }_{13} \mathrm{Si}$ bien es cierto que esta labor inspectora se ha atenuando desde 2002, como señala J. Dorodnova, «¿Quién pertenece a Letonia?», Tempo Exterior, núm. 5 (2002), pp. 33-53.

${ }^{14}$ De este tratado internacional son parte todos los Estados secesionados, incluido Estonia, en este caso desde 2005. 
rales rusohablantes han sido impugnados en las Naciones Unidas y en el Consejo de Europa. En el primer ámbito, el Comité de Derechos Humanos del Pacto Internacional de Derechos Civiles y Políticos (en adelante, PIDCP) se pronunció al respecto en el caso Antonina Ignatane v. Letonia (núm. 884/1999, de 2002), en el que consideró vulnerados los arts. 2 y 25 del Pacto de Nueva York de 1966. Entendió el Comité que la verificación por un inspector unos días antes de las elecciones municipales del nivel de conocimiento del estonio de esta candidata en 1997, cuando ya lo tenía acreditado por un panel de cinco especialistas cuatro años antes, resultó inapropiado. Tampoco compartió el argumento del Estado de que es imprescindible el conocimiento del más alto nivel de estonio para el ejercicio de la gestión municipal, especialmente cuando no hay otros requisitos de formación específica ni se exigen ambos en otras elecciones.

Del mismo modo, en el asunto Podzolzina v. Letonia (Sentencia núm. 46726/1999, de 9 de abril de 2002), el TEDH entendió que «a los efectos de la aplicación del art. 3 (del Protocolo núm. 1), toda legislación electoral debe evaluarse a la luz de la evolución política del país en cuestión, de modo que las características que serían inaceptables en el contexto de un sistema pueden estar justificadas en el contexto de otro. Sin embargo, el margen de la apreciación del Estado a este respecto está limitado por la obligación de respetar el principio fundamental del art. 3, a saber, la libre expresión de la opinión del pueblo en la elección del legislador». Por ello, «teniendo en cuenta el margen de apreciación del Estado demandado, la Corte concluye que exigir que un candidato a las elecciones al parlamento nacional tenga suficiente conocimiento del idioma oficial persigue un objetivo legítimo». No obstante, ese control —entiende el tribunal- debe ser realizado por un organismo que pueda proporcionar un mínimo de garantías de su imparcialidad. Del mismo modo, la discreción de dicho organismo inspector no debe ser demasiado amplia; por el contrario, debe estar circunscrito de forma lo más reglada posible en la legislación nacional. Por ello - añade- el procedimiento para decidir la inelegibilidad de un candidato debe ser tal que garantice una decisión justa y objetiva y evite cualquier abuso de poder por parte de la autoridad competente. El tribunal considera que, teniendo en cuenta que la candidata tenía un certificado anterior sobre su conocimiento del idioma emitido por cinco especialistas, resulta extraño que la responsabilidad total de evaluar el conocimiento lingüístico de la solicitante se dejase en manos de un funcionario. Además, el Tribunal no puede sino expresar «su sorpresa por el hecho — relacionado por la demandante y no cuestionado por el 
gobierno- de que durante el examen la demandante fuera interrogada principalmente sobre los motivos de su orientación política, un tema que evidentemente no tenía nada que ver con el requisito de que ella debería tener un buen conocimiento del letón». Por ello concluye que «cualquiera que fuera el objetivo del segundo examen, el procedimiento aplicado a la solicitante era, en cualquier caso, incompatible con los requisitos de equidad procesal y seguridad jurídica satisfecho en relación con la elegibilidad de los candidatos» y que «la decisión de excluir a la demandante de la lista de candidatos no puede considerarse proporcionada a ningún objetivo legítimo invocado por el gobierno».

También puede haber otras limitaciones relacionadas con la pertenencia a determinados partidos políticos. Así, la Ley para las Elecciones Parlamentarias de 25 de mayo de 1995 de Letonia establecía en su Sección 5. ${ }^{a}$ como impedimento para ser elegible «haber participado activamente después del 13 de enero de 1991 en el PCUS (CPL), el Frente Internacional de Trabajadores de la RSS de Letonia, el Consejo Unido de Colectivos Laborales, la Organización de Veteranos de Guerra y Trabajo o el Comité de Rescate Público de Letonia, o en sus comités regionales». Esta legislación electoral fue sustituida en lo que respecta exclusivamente a las elecciones al Parlamento Europeo, después de entrar en la UE, por la Ley de 29 de enero de 2004, que suprimió este previsión. No obstante, aunque en primera instancia el TEDH entendió que no era proporcionado negar el sufragio pasivo de forma permanente a un ciudadano por hechos acontecidos en el momento de la consecución de la independencia sin mediar una condena penal por crímenes contra el Estado, sin embargo, la Gran Sala aceptó que «para garantizar la estabilidad y la efectividad de un sistema democrático se puede requerir que el Estado tome medidas específicas para protegerse», siempre y cuando se haga de forma proporcionada y no discriminatoria ${ }^{15}$.

Los problemas derivados de la denegación de la nacionalidad se producen en algunos casos no solo respecto de las minorías originarias del Estado predecesor, sino también respecto de la población afín étnicamente al

${ }^{15}$ En el caso Ždanoka v. Letonia (asunto núm. 58278/00, Sentencia de 16 de marzo de 2006), cuando analiza la existencia o no de proporcionalidad en la restricción legal, expone que «aunque las partes no están de acuerdo en cuanto a si la restricción impugnada constituyó una medida preventiva o punitiva», el Tribunal acepta en el presente caso que las autoridades nacionales de Letonia, tanto legislativas como judiciales, están en mejores condiciones para evaluar las dificultades con que se enfrenta el establecimiento y la salvaguardia del orden democrático. 
nuevo Estado que se considera poco o nada movilizada con el nuevo régimen nacionalista por haber formado parte de su Administración o de las Fuerzas Armadas o de la Policía o por tener intereses económicos en el Estado matriz. Así ha ocurrido en Eritrea, donde en el referéndum organizado en 1993 bajo supervisión de la ONU, del millón de inscritos voluntariamente en el censo, unos 66.000 eran eritreos residentes en Etiopía (principalmente empleados públicos). Proclamado el nuevo Estado, las autoridades etíopes les retiraron su nacionalidad, entendiendo que habían optado por la de Eritrea al participar en el referéndum, pero las autoridades eritreas - que no querían en el electorado a antiguos funcionarios, empresarios con intereses en Etiopía e incluso políticos, todos ellos presuntamente desleales- consideró que no eran tampoco nacionales suyos por carecer de la residencia. En 1999, no permitida su entrada en Eritrea, el gobierno de Etiopía ordenó la detención de unos 70.000 «apátridas de origen eritreo» residentes en su país, que, sin embargo, no lo eran para el gobierno de Asmara, que fueron previamente despedidos de sus trabajos ${ }^{16}$ y posteriormente objeto de incautación de sus bienes, procediéndose a su deportación a través de Djibuti. En 2004 la Comisión de Reclamaciones para Eritrea-Etiopía, un órgano impulsado por la Unión Africana y la ONU después del nuevo conflicto armado (por cuestiones fronterizas) de 1998-2000, declaró la ilegalidad de la sustracción de su nacionalidad, lo que motivó que en 2003 Etiopía les permitiera recuperar la nacionalidad de este país, sin que todavía haya una respuesta de Eritrea.

En algunos de estos países surgidos de procesos de secesión se han planteado diversas opciones para favorecer o para obstaculizar la representación parlamentaria de las minorías. Uno de los métodos utilizados ha sido la prohibición de partidos políticos de base étnica o religiosa: en Albania, la legislación electoral vigente entre 1992 y 2000 no permitía los partidos políticos de base étnica para impedir la representación de la minoría

${ }^{16}$ Ese despido masivo fue objeto de una reclamación presentada en 2001 ante la OIT por incumplimiento de los Convenios núms. 111 y 158 sobre terminación de la relación de trabajo. En el informe de 12 de noviembre de 2001 del Comité OIT del Convenio contra la discriminación en el trabajo de 1958 se afirmaba que: «Se informa que Etiopía deportó a más de 70.000 nacionales de Eritrea y a ciudadanos etíopes de origen eritreo, y que Eritrea también deportó a más de 40.500 nacionales etíopes. Según los alegatos, esos trabajadores desplazados fueron despedidos de manera sumaria de sus empleos, se les denegó el derecho de recurrir la terminación de su relación de trabajo y su deportación, y se les denegaron los sueldos y las prestaciones de empleo devengadas. Además, se alega que ambos países se han apoderado de los efectos personales e inmobiliarios de los nacionales del otro país» (punto 7). 
griega (8 por 100 de la población), y lo mismo sucede en Bulgaria, desde su Constitución de 1991, para dificultar la participación política de los turcos (8 por 100). Otra forma de dificultar su acceso a los parlamentos nacionales ha consistido en establecer umbrales mínimos para obtener diputados: en Lituania era en 1992 un 4 por 100 y se elevó en 1996 al 5 por 100, en perjuicio del 8,4 por 100 de rusos, 7,75 por 100 de polacos y 1,5 por 100 de bielorrusos; por el contrario, en Serbia, inicialmente, la barrera era del 5 por 100 en 2000, pero posteriormente se ha modificado para permitir la representación con tan solo un 0,004 por 100 de los votos a nivel estatal, lo que ha permitido el fácil acceso de húngaros (3,8 por 100 en 2012) y, en menor medida, de bosnios y albaneses. También han servido a estos fines obstáculos administrativos, como la necesidad en Moldavia de presentar avales por un alto porcentaje de distritos electorales, en perjuicio de las minorías de implantación territorial, como ucranianos (11 por 100) y rusos (10 por 100). Por último, también se ha recurrido a la manipulación de las circunscripciones electorales, como en Macedonia, donde se ha practicado hasta 2002 una «concentración reductiva» consistente en disminuir el número de distritos con población mayoritaria albanesa $(25 \text { por } 100)^{17}$. En cualquier caso, instancias internacionales como el TEDH no pueden valorar si los sistemas electorales de los Estados favorecen o no la representación de las minorías, pues son cuestiones que entran de lleno en el margen de apreciación estatal en lo que respecta al derecho a unas elecciones libres consagrado en el art. 3 del Protocolo adicional primero de $1952^{18}$.

Como ya expusimos en otro trabajo ${ }^{19}$, la máxima expresión de la discriminación étnica es la Constitución de Bosnia-Herzegovina de 21 de noviembre de 1995, negociada en el marco de los Acuerdos de Paz de Dayton, pues no solo consagra la segregación étnico-política del Estado entre serbo-bosnios y serbo-croatas y bosnios musulmanes, sino que excluye de este diseño constitucional a las otras minorías, como los gita-

${ }^{17}$ Cfr. C. Flores Juberías, «Sistemas electorales y minorías étnicas en la Europa Central y del Este: de la transición a la consolidación de la democracia», Revista de Estudios Políticos, núm. 166 (2014), pp. 41-67. Otras formas de discriminación son las derivadas del otorgamiento de un número fijo de diputados a unas minorías y a otras, sin embargo, no. Es el caso de los 5 diputados albaneses ( 5 por 100 de la población); de los 81 del parlamento de Montenegro (desde 2006), sin que tengan el mismo trato los serbios (32 por 100) o los bosnios $(7,8$ por 100), y también de los húngaros $(0,4$ por 100) e italianos $(0,2$ por 100$)$ de Eslovenia (desde 1991), con un diputado fijo cada uno entre 90, no siendo así con croatas (3 por 100) ni serbios (2 por 100). Vid. también B. ARP, Las minorías nacionales..., op. cit., p. 236.

${ }_{18}$ Cfr. B. ArP, Las minorías nacionales..., op. cit., p. 375.

19 A. G. López Martín y J. A. Perea Unceta, Creación de Estados..., op. cit., pp. 279-280. 
nos y judíos. En Sentencia de 21 de diciembre de 2009, la Gran Sala del TEDH consideró, en el caso Sejdić y Finci v. Bosnia y Herzegovina (asuntos 27996/06 y 34836/06), que la previsión efectuada a favor de aquellas comunidades enfrentadas en la guerra civil de 1992-1995 de reservar y repartir entre ellas la Cámara de los Pueblos y la Presidencia no tiene justificación en la actualidad y constituye una discriminación injustificable que perjudica a los demandantes (de las minorías romaní y judía), violando manifiestamente el art. 14 del Convenio de Roma de 1950 y su Protocolo núm. 12.

Estos ejemplos ponen de manifiesto una tendencia en los Estados creados por secesión, muy particularmente en los surgidos desde 1990, a tratar a sus minorías, en el mejor de los casos, sin un reconocimiento de su diferenciación (especialmente lingüística) y, en el peor, dificultando su integración en la nueva sociedad, con trabas muy importantes en el acceso a la nacionalidad, en lo que respecta al sufragio activo o pasivo y al desempeño de la función pública o incluso de determinadas actividades laborales y profesionales. Por su gravedad, destaca la situación inicial de las minorías rusas y de otras zonas de la antigua Unión Soviética en Estonia y Letonia, con avances - todavía insuficientes- por la presión de la UE y la OSCE.

\section{LA PROBLEMÁTICA DE LA SUCESIÓN DE TRATADOS SOBRE DERECHOS HUMANOS EN LOS SUPUESTOS DE SECESIÓN}

Estas situaciones de falta de protección de los derechos humanos de las minorías se producen especialmente o con mayor gravedad en la etapa posterior a la independencia de estos Estados. Es por ello que, en los supuestos de secesiones aceptadas internacionalmente, el primer test que se plantea gira en torno a la institución de la sucesión de tratados internacionales para saber si es posible evitar esas situaciones iniciales de ausencia de normas internacionales protectoras, y no solo primarias o de reconocimiento, sino también secundarias o de supervisión.

Puesto que hay una transformación en la subjetividad estatal, hemos de situarnos en la institución de la sucesión de Estados en materia de tratados internacionales. La sucesión se plantea en un supuesto típico de cambio en la titularidad estatal de un territorio o, dicho en los términos del Convenio de Viena de 1978 sobre sucesión de Estados en materia de tratados, 
de «sustitución de un Estado por otro en la responsabilidad de las relaciones internacionales de un territorio» [art. 1.2.b)]. El primer obstáculo con el que nos encontramos es su no aplicación a los supuestos de secesión, ya que, según su art. 6, «la presente Convención se aplicará únicamente a los efectos de una sucesión de Estados que se produzca de conformidad con el Derecho internacional y, en particular, con los principios de Derecho internacional incorporados en la Carta de las Naciones Unidas», y la secesión se caracteriza precisamente por realizarse sin el consentimiento del Estado matriz, vulnerando, por tanto, el principio de integridad territorial, consustancial al principio de soberanía estatal, cuando no el de prohibición del uso de la fuerza ${ }^{20}$.

Esta consideración es particularmente pertinente, puesto que el Convenio de Viena de 1978, si bien recoge para los Estados surgidos de la descolonización la «regla de la tabla rasa», sin embargo, para los separados dispone «el principio de la continuidad». Efectivamente, en su art. 34.1 dispone que «cuando una parte o partes del territorio de un Estado se separen para formar uno o varios Estados, continúe o no existiendo el Estado predecesor: a) todo tratado que estuviera en vigor en la fecha de la sucesión de Estados respecto de la totalidad del territorio del Estado predecesor continuará en vigor respecto de cada Estado sucesor así formado». El Convenio se refiere a los casos de separación, sin distinguir ni precisar si incluye a las separaciones no consentidas, que son propiamente secesiones, y aunque no se debería aplicar en estos últimos supuestos por lo dicho anteriormente, lo cierto es que ni en los trabajos preparatorios ni en la práctica posterior en aplicación del tratado se ha hecho esta distinción.

El segundo obstáculo al respecto tampoco es menor, puesto que la vigencia de ese principio de la continuidad en lo que respecta a los tratados sobre derechos humanos solo vincularía por vía convencional a sus veintidós Estados Parte (entre ellos algunos secesionados, como los exyugoslavos y Estonia). Respecto a su vigencia como norma consuetudinaria, no solo se discute que dicho tratado fuera realmente codificador de una costumbre internacional anterior ${ }^{21}$, sino que la práctica posterior es realmente poco uniforme y general al respecto. En este sentido, como señala Aust en un informe de Naciones Unidas de 2010, «las reglas de la Convención relativas a la fragmentación de Estados tampoco reflejaban la práctica moderna de

${ }^{20}$ Sobre el respeto a la legalidad internacional como condición necesaria para adquirir el estatus de Estado vid. ibid., pp. 55 y ss.

${ }_{21}$ En esta línea vid. L. García-Corrochano Moyano, «Sucesión de Estados en materia de tratados», Agenda Internacional, vol. 3 , núm. 7 (1997), pp. 121-132. 
los Estados, en particular la gran variedad de situaciones registradas a finales del siglo xx. En 1990 se produjo la reunificación de Alemania. El estallido de la Unión Soviética ocurrió en 1991, mientras que el de Yugoslavia tuvo lugar fundamentalmente entre 1992 y 1993. El llamado divorcio de terciopelo de Checoslovaquia data de 1993. En resumen, antes de la década de los noventa no había mucha práctica reciente en la que basarse. Aunque ciertas partes de la Convención de 1978 podrían haberse utilizado en la elaboración de algunos acuerdos bilaterales de sucesión —un buen ejemplo en este sentido sería el claro respaldo a lo dispuesto en el párrafo 1 del art. 34 (sucesión de Estados en caso de separación de partes de un Estado) en la práctica seguida por los Estados sucesores de la ex Checoslovaquia-, lo más probable es que su influencia y su importancia práctica sigan estando muy lejos de las de la Convención de 1969. A pesar de que en sus Opiniones núms. 1 y 9 de la Comisión de Arbitraje de la Conferencia para la Paz en Yugoslavia (también conocida como "Comisión Badinter") indicase que la Convención de 1978 encarnaba los principios del Derecho internacional, el art. 34 no debe considerarse necesariamente como un reflejo del Derecho internacional consuetudinario. Por más que la Convención de 1978 sea un ejemplo de desarrollo progresivo del Derecho internacional, las reglas consuetudinarias internacionales sobre la sucesión de Estados en materia de tratados se aplican a la mayoría de los Estados y, sin embargo, no están recogidas en el texto de la Convención de 1978, que, en consecuencia, no puede considerarse una guía fiable de tales reglas de Derecho consuetudinario ${ }^{22}$. Efectivamente, la práctica anterior a su celebración es muy escasa y diversa, impidiendo que ciertamente pueda apreciarse la existencia de una norma consuetudinaria. Así, Bélgica (1830), Cuba (1898), Panamá (1903) y Finlandia (1918) ${ }^{23}$ aplicaron la tabla rasa sin oposición de la comunidad internacional. Y en las últimas décadas, mientras que los Estados exyugoslavos de Eslovenia, Croacia, Bosnia-Herzegovina y Macedonia se declararon mayoritariamente continuadores de las obligaciones de Yugoslavia, los exsoviéticos no se consideraron vinculados por los escasos tratados celebrados por la Unión Soviética y prefirieron optar por adherirse a los mismos a título de sucesores ${ }^{24}$.

22 Vid. A. Aust, Convención de Viena sobre la sucesión de Estados en materia de tratados, New York, United Nations, 2010.

${ }^{23}$ Respecto de estos casos cfr. C. E. Odriozola Mariscal, «Tratados y sucesión de Estados», Ars Iuris, núm. 22 (1999), pp. 184-216.

${ }^{24}$ Vid. H. Andaluz Vegacenteno, «El derecho de la sucesión de Estados», Revista de la Facultad de Ciencias Sociales y Jurídicas de Elche, vol. I, núm. 2 (2007), pp. 258-293. 
Cuestión muy distinta es que buena parte de la doctrina defienda la conveniencia de que haya una «sucesión automática» ${ }^{25}$ que evite situaciones de desprotección de los derechos humanos de la población ${ }^{26}$ como las que hemos señalado en los momentos críticos de transición a un nuevo Estado, proceso que puede ser muy breve o que puede dilatarse en el tiempo por la oposición del Estado matriz y de la comunidad internacional.

En esta línea estaría la corriente doctrinal, especialmente latinoamericana ${ }^{27}$, que defiende la vigencia en el ámbito del Derecho internacional de los derechos humanos del principio pro bomine o pro persona, según el cual en la interpretación o adecuación normativa debe buscarse que se alcance el resultado que proteja mejor a las personas ${ }^{28}$. Son numerosas las sentencias de la Corte Interamericana de Derechos Humanos que se suman a esta doctrina ${ }^{29}$, pues entiende, «al igual que la Corte Europea de Derechos Humanos, que los tratados de derechos humanos son instrumentos vivos, cuya interpretación tiene que acompañar la evolución de los tiempos y las condiciones de vida actuales. Tal interpretación evolutiva es consecuente con las reglas generales de interpretación consagradas en el art. 29 de la Convención Americana, así como las establecidas por la Convención de Viena sobre el Derecho de los Tratados. En este sentido, al interpretar la Convención debe siempre elegirse la alternativa más favorable para la tutela de los derechos protegidos por dicho tratado según el

25 Vid. O. Schachter, «State Succession: The Once and Future Law», Virginia Journal of International Law, vol. 33 (1993), pp. 253 y ss, y M. T. KAmINGA, «State Succession in Respect of Human Rights Treaties», European Journal of International Law, vol. 7 (1996), pp. 469-484.

${ }^{26} \mathrm{Al}$ margen de los derechos humanos que son de naturaleza imperativa, indisponibles e inderogables, y que son un pequeño núcleo del Pacto Internacional de Derechos Civiles y Políticos de 1966 (desde el derecho a la vida al de respeto a la integridad física) y la mayor parte de los derechos reconocidos en tiempo de guerra a beligerantes, prisioneros y población civil en los Convenios de Ginebra de 1949 y sus Protocolos, cuya contravención suponen crímenes de guerra, así como de las conductas igualmente proscritas como crímenes internacionales de genocidio y de lesa humanidad.

27 Entre otros, vid. H. Gros Espiell, «Los métodos de interpretación utilizados por la Corte Interamericana de Derechos Humanos en su jurisprudencia contenciosa», en R. Nieto Navia (ed.), La Corte y el sistema interamericano de derechos bumanos, San José de Costa Rica, CIDH, 1994, pp. 39 y ss., y A. A. C. TRINDADE, Direito internacional e direito interno: sua interação na proteção dos direitos humanos, San José de Costa Rica, 1996 y 2004.

${ }^{28}$ Cfr. Z. DRnAS De ClÉMENT, «La complejidad del principio pro homine», Jurisprudencia Argentina, núm. 12 (2015), pp. 98-111.

29 Entre otras, en los casos Baena Ricardo y otros v. Panamá (Sentencia de 28 de noviembre de 2003), Herrera Ulloa v. Costa Rica (Sentencia de 2 de julio de 2004) y Ricardo Canese v. Paraguay (Sentencia de 31 de agosto de 2004). 
principio de la norma más favorable al ser humano» ${ }^{30}$. Como señala Pascual Vives, «tanto el TEDH como la CIDH han reconocido que el Convenio de Roma y el Pacto de San José, respectivamente, deben ser interpretados de manera evolutiva, ser sensibles a los cambios que tienen lugar en los sistemas legislativos de sus Estados Parte y, en general, atender a los desarrollos sociales experimentados por el Derecho internacional de los derechos humanos, pues ambos tratados constituyen instrumentos vivos o "living instrument(s) which [...] must be interpreted in the light of present-day conditions". El límite a esta práctica hermenéutica evolutiva reside, como indicó el Tribunal de Estrasburgo en Johnston y otros c. Irlanda, en la imposibilidad de modificar el tenor del tratado internacional introduciendo o incorporando un derecho no previsto inicialmente por los Estados Parte. Además, como resultado de la misma cabría introducir ciertos límites al ejercicio de algunos derechos otorgados a los particulares» ${ }^{31}$.

No obstante, observamos que este principio se aplica en situaciones de interpretación de normas internacionales en la que son parte los Estados, pero no en los casos, que estamos comentando, de hechos producidos respecto de Estados que no participan en las mismas. Solo en algunos pocos casos el TEDH ha sobrepasado los límites tradicionales del principio de soberanía estatal y del consecuente principio de relatividad de los tratados internacionales, o bien reconociendo un incipiente y todavía difuso «common law» europeo en el ámbito de los derechos humanos, o bien aplicando una aún poco sistemática doctrina de los derechos adquiridos que beneficia a la población de territorios con cambios de titularidad en su soberanía.

Respecto de la primera tendencia, en el caso Demir y Baykara $v$. Turquía (asunto núm. 34503/97), la Gran Sala en su Sentencia de 12 de noviembre de 2008, párrafo 76, recuerda que — como ya expuso en el asunto Saadi v. el Reino Unido (asunto núm. 13229/03) — cuando se considera el objeto y el propósito de las disposiciones de la Convención, también ha de tenerse en cuenta el Derecho internacional al respecto. De tal modo que si hay un conjunto de reglas y principios que son aceptados por la gran mayoría de los Estados, las normas de ese «Derecho común» internacional o nacional de los Estados europeos reflejan una realidad que la Corte no puede

30 Asunto La masacre de Mapirán v. Colombia, Sentencia de 15 de septiembre de 2005, Serie C, núm. 134, párr. 106.

31 Vid. F. J. PASCUAL VIVES, «Consenso e interpretación evolutiva de los tratados regionales de derechos humanos», Revista Española de Derecho Internacional, vol. 66, núm. 2 (2014), p. 126. 
ignorar cuando se le pide aclarar el alcance de una disposición del Convenio de Roma de 1950.

En relación con la segunda doctrina, destaca, sin duda, la consideración efectuada por el TEDH en el asunto Bijelić v. Montenegro and Serbia (asunto núm. 11890/05, Sentencia de 28 de abril de 2009), al entender que las personas que viven en un territorio continúan estando protegidas por los tratados internacionales sobre derechos fundamentales pese a los cambios de soberanía que se produzcan respecto de aquel por posteriores disoluciones, separaciones o secesiones. En efecto, recuerda que «el Comité de Derechos Humanos ha dejado claro, en el contexto de las obligaciones derivadas del Pacto Internacional de Derechos Civiles y Políticos, que los derechos fundamentales protegidos por los tratados internacionales "pertenecen a las personas que viven en el territorio del Estado Parte" en cuestión (párr. 58). En particular, "una vez que se otorga a las personas la protección de los derechos consagrados en el Pacto, dicha protección incumbe al territorio y sigue perteneciendo a ellos, independientemente del cambio de gobierno del Estado Parte, incluido el desmembramiento en más de un Estado o sucesión de Estados" (Observación general núm. 26, Continuidad de las obligaciones, 12 de agosto de 1997, CCPR/C/2/Rev. 1/Add. 8/Rev. 1)» $\gg^{32}$, y coincidiendo con esta doctrina concluye que «en vista de lo anterior, dados los requisitos prácticos del art. 46 de la Convención, así como el principio de que los derechos fundamentales protegidos por los tratados internacionales de derechos humanos deben pertenecer a las personas que viven en el territorio del Estado Parte interesado a pesar de su posterior disolución o sucesión, el Tribunal considera que tanto el Convenio como el Protocolo núm. 1 deben considerarse continuamente vigentes en Montenegro desde el 3 de marzo de 2004, entre el 3 de marzo de 2004 y el 5 de junio de 2006, y posteriormente» (párr. 69).

32 Vid. también, en este sentido, las Resoluciones 1993/23, 1994/16 y 1995/18 de la Comisión de Derechos Humanos de la ONU y la Decisión de 7 de octubre de 1992 del Comité de Derechos Humanos del PIDCP UN Doc. A/49/40, en relación, en este último documento, con los Estados surgidos del desmembramiento de la Unión Soviética y la disolución de Yugoslavia. 


\section{LA ACTUACIÓN INSTITUCIONAL EN RELACIÓN CON LAS VIOLACIONES DE LOS DERECHOS HUMANOS EN LAS ENTIDADES DE FACTO}

El TEDH también ha actuado en múltiples ocasiones en situaciones de vulneración de los derechos fundamentales de las personas en los que las violaciones de las normas del Consejo de Europa se han producido en entidades secesionadas de Estados miembros y no aceptadas internacionalmente, como RTNC ${ }^{33}$, Chechenia ${ }^{34}$, Transnistria ${ }^{35}$ o Nagorno-Karabaj ${ }^{36}$. Se trata de secesiones frustradas o rechazadas en las que una parte del territorio de un Estado (Chipre, Rusia, Moldavia o Azerbaiyán), en el contexto de un conflicto armado - interno como en Chechenia o alentado o apoyado por otros países como en los restantes-, queda bajo la autoridad de una entidad de facto no reconocida por el gobierno de ese Estado ni por la generalidad de la comunidad internacional. Si bien Chechenia se mantuvo como independiente solo entre 1992 y 2000, hasta que Rusia recuperó el control del territorio, en otros casos como los de Transnistria, Nagorno-Karabaj, Osetia del Sur y Abjasia es Rusia quien soporta militar y diplomáticamente y asegura la viabilidad económica de estos enclaves desde la desaparición de la Unión Soviética en 1991. Esta circunstancia, también aplicable a Turquía respecto de la RTNC desde 1983, hace que en estos casos la determinación, como veremos, de la responsabilidad internacional en materia de vigencia de los derechos humanos sea aún más compleja que en otros escenarios en los que hay una autoridad gubernamental de facto que administra con exclusividad ese territorio, como en Somalia desde 1991 o en Anjouán entre 1997 y 2008, hasta la intervención militar de la Unión Africana que restableció la integridad territorial de las Comoras.

Las opciones posibles de exigencia de cumplimiento de las obligaciones internacionales son el Estado matriz, el Estado interviniente o la entidad territorial. La primera opción para el TEDH es el Estado matriz, pues entiende el tribunal que rige la presunción general de que todo Estado es

\footnotetext{
${ }^{33}$ En el caso Solomou and Others v. Turkey (asunto núm. 36832/97), Sentencia de 24 de junio de 2008.

${ }_{34}$ En el caso Akhmadova and Akhmadov v. Russia (asunto núm. 20755/04), Sentencia de 25 de septiembre de 2008.

35 En el caso Kommersant Moldovy v. Moldova (asunto núm. 41827/02), Sentencia de 9 de enero de 2007. de 2010.

${ }^{36}$ En el caso Fatullayev v. Azerbaijan (asunto núm. 40984/07), Sentencia de 22 de abril
} 
responsable de lo que sucede en su territorio. Así lo determinó en el caso Ilaşcu and others v. Moldavia y Rusia (asunto núm. 48787/99), Sentencia de 8 de julio de 2004, en la que señala que cuando el art. 1 del Convenio de Roma dice que «las Altas Partes Contratantes reconocen a toda persona dependiente de su jurisdicción los derechos y libertades definidos en el título I del presente Convenio», las palabras «dependiente de su jurisdicción» deben entenderse en el Derecho internacional aceptando que la competencia jurisdiccional de un Estado es principalmente territorial y que se presume que se ejerce normalmente en todo el territorio del Estado (párr. 312) ${ }^{37}$.

Para el Tribunal de Estrasburgo esta presunción solo cede en circunstancias excepcionales, como señaló en el caso Mozer v. República de Moldavia y Rusia (asunto núm. 11128/10, Sentencia de 23 de febrero de 2016, párr. 97), especialmente cuando un Estado no puede ejercer su autoridad en una parte de su territorio, lo que puede deberse a la ocupación militar por las fuerzas armadas de otro Estado que controla efectivamente el territorio en cuestión, actos de guerra o rebelión, o las actividades de otro Estado que apoya a una entidad separatista ${ }^{38}$. Esta situación de ocupación militar libera al Estado titular de la soberanía territorial de su responsabilidad internacional y hace, de conformidad con las normas sobre ocupación militar establecidas en los Convenios de Ginebra de 1949, que sea atribuible al Estado ocupante. Efectivamente, el IV Convenio de Ginebra relativo a la protección debida a las personas civiles en tiempo de guerra establece, entre otros, en su art. 27 la obligación de la potencia ocupante de proteger a todos los civiles, y prescribe en el 29 que «la parte en conflicto en cuyo poder haya personas protegidas es responsable del trato que les den sus agentes, sin perjuicio de las responsabilidades individuales en que se pueda incurrir». En Catan y otros v. República de Moldavia y Rusia (asunto núm. 43370/04, Sentencia de 19 de octubre de 2012), el TEDH recuerda que la Corte Internacional de Justicia (en adelante, CIJ) en su Opinión Consultiva de 21 de junio de 1971, sobre las consecuencias legales para los Estados de la continua presencia de Sudáfrica en Namibia a pesar de lo dispuesto en la Resolución 276/1970, declaró que «Sudáfrica, siendo responsable de haber creado y mantenido una situación que

37 También en otros, como en el caso Solomou y otros $v$. Turquía (asunto núm. 36832/97), Sentencia de 24 de junio de 2008, párr. 37, y en el caso Sargsyan v. Azerbaijan (asunto núm. 40167/06), Sentencia de 16 de junio de 2015, párrs. 127 y ss.

38 El TEDH cita a este respecto los casos Chipre v. Turquía (asunto núm. 25781/94), Loizidou v. Turquía (excepciones preliminares), Sentencia de 23 de marzo de 1995, y Bankovic y otros v. Bélgica y otros (asunto núm. 52207/99). 
la Corte ha determinado que es ilegal, tiene la obligación de poner fin a la misma. Por tanto, está obligada a retirar su gestión del territorio de Namibia. Al mantener la actual situación ilegal y al ocupar el territorio sin título, Sudáfrica incurre en responsabilidades internacionales derivadas de una continua violación de una obligación internacional. También es responsable de cualquier violación de los derechos del pueblo de Namibia o de sus obligaciones internacionales. El hecho de que Sudáfrica no disponga de ningún título para gestionar el territorio no lo libera de sus obligaciones y responsabilidades, en virtud del Derecho internacional hacia otros Estados, en cuanto al ejercicio de sus facultades en relación con el territorio. El control físico de un territorio y no la soberanía o la legitimidad del título es el fundamento de la responsabilidad del Estado por actos que afecten a otros Estados» (párr. 118).

De tal modo que también es atribuible la responsabilidad internacional, en segundo lugar, al Estado ocupante de una parte del territorio. En Loizidou v. Turquía expresó el TEDH que «podría considerarse que un Estado ejerce jurisdicción extraterritorial si: a) continúa ejerciendo el control a través de las autoridades locales subordinadas y $b$ ) mantiene el control sobre todo el territorio debido a la presencia de un gran número de tropas y "ejerció prácticamente un control global" sobre el "territorio relevante" (párr. 62). Para ello es necesario constatar la fuerza de su presencia militar en el territorio, la importancia de la ayuda militar, económica y política a la administración local subordinada, y la influencia y control sobre la región». En el caso Chiragov y otros v. Armenia (asunto núm. 13216/05, Sentencia de 16 de junio de 2015) ha precisado que esta ocupación militar puede ser también por «consentimiento, invitación o aquiescencia del gobierno del territorio, ejerciendo el ocupante las funciones públicas que normalmente ejercería dicho gobierno» (párr. 168). El TEDH ha reiterado a este respecto en varios casos que no debe confundirse esta institución con la general de la responsabilidad internacional. En esta línea, en el asunto Mozer expresa que, «como demuestra el resumen de la jurisprudencia del Tribunal antes expuesta, la prueba para establecer la existencia de "jurisdicción" en virtud del art. 1 del Convenio nunca se ha equiparado con la prueba del establecimiento de la responsabilidad de un Estado por un hecho internacionalmente ilícito en virtud del Derecho internacional» ${ }^{39}$ (párr. 107). Así lo enten-

39 En el asunto Mozer (párr. 92) explica, para el caso concreto, la diferente concepción del TEDH sobre esta cuestión, pues «el concepto de «control efectivo» aplicado por la Corte al establecer si un Estado ejercía jurisdicción extraterritorial estaba en desacuerdo con su significado en el Derecho internacional público. La noción de «control efectivo 
dió también en el caso Chigarov al considerar que el NKR (la República de Nagorno-Karabaj) y su administración sobreviven en virtud del apoyo militar, político, financiero y de otra índole de Armenia. Estado que, en consecuencia, ejerce un control efectivo sobre ese territorio; por tanto, los asuntos denunciados están dentro de la jurisdicción de Armenia a los efectos del art. 1 del Convenio (párr. 186).

Por otro lado, la responsabilidad, y aquí sí recurre sin reservas a la jurisprudencia de la CIJ, también es exigible cuando el Estado ocupante actúa mediante personas o grupos de personas que — sin ser formalmente órganos suyos- actúan de hecho bajo su control, con referencia expresa a la Sentencia de 27 de junio de 1986 en el asunto de las actividades militares y paramilitares en y contra Nicaragua (Nicaragua v. Estados Unidos) y la Sentencia de 14 de febrero de 2007 en el asunto de la aplicación de la Convención para la prevención y sanción del delito de genocidio (Bosnia-Herzegovina v. Serbia).

y general» apareció por primera vez en la jurisprudencia de la Corte Internacional de Justicia, pero tenía un significado diferente. Comparando la situación actual con la del caso relativo a las actividades militares y paramilitares en y contra Nicaragua (asunto Nicaragua v. Estados Unidos de América, Sentencia de la Corte Internacional de Justicia de 27 de

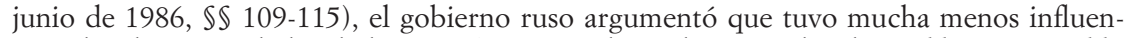
cia sobre las autoridades de la MRT (MRT son las siglas en inglés de Moldavian Republic of Transdniestria) que los Estados Unidos de América sobre los rebeldes en Nicaragua, especialmente en términos de la fuerza de su presencia militar en la MRT. De hecho, Rusia fue uno de los mediadores del conflicto entre Moldavia y la autoproclamada MRT. La CIJ confirmó su posición en el caso relativo a la aplicación de la Convención para la Prevención y la Sanción del Delito de Genocidio (asunto Bosnia y Herzegovina c. Serbia y Montenegro, Sentencia de 26 de febrero de 2007, «el caso del genocidio en Bosnia»). La noción de «control general» había sido desarrollada por el Tribunal Penal Internacional para la ex Yugoslavia. La interpretación del Tribunal de esta noción difiere de las interpretaciones de otros tribunales internacionales: «Además, Rusia nunca se había ocupado de ninguna parte del territorio de Moldavia. No se puede decir que Rusia ejerció jurisdicción en el presente caso, donde el territorio estaba controlado por un gobierno de facto que no era un órgano o instrumento de Rusia y que no dependía de Rusia de ninguna manera. Por el contrario, Rusia considera que la MRT es una parte integral de la República de Moldavia. La presencia militar rusa estaba restringida a un número limitado de fuerzas de paz; por tanto, no había motivos para concluir que ejerció el control a través de la fuerza de su presencia militar». Y concluye afirmando que: «La Corte mantiene sus conclusiones en Ilaşcu $y$ otros, Ivanţoc y otros y Catan y otros en el sentido de que la MRT solo puede continuar existiendo, y para resistir los esfuerzos moldavos e internacionales para resolver el conflicto y llevar la democracia y el Estado de Derecho a la región, debido al apoyo militar, económico y político de Rusia. En estas circunstancias, el alto nivel de dependencia de la MRT en el apoyo de Rusia proporciona una fuerte indicación de que Rusia continúa ejerciendo un control efectivo y una influencia decisiva sobre las autoridades de la MRT. De ello se desprende que la demandante en el presente asunto es competencia de Rusia en virtud del art. 1 del Convenio» (párrs. 110 y 111). 
Esto no significa, sin embargo, que el Estado titular no tenga ninguna responsabilidad por hechos ocurridos en el territorio secesionado de facto, puesto que el Tribunal también verifica que haya adoptado -o intentado adoptar al menos- con diligencia todas las medidas de índole diplomática, económica, judicial, administrativa o de otra clase respecto de la situación de que se trate o de las personas afectadas. Así lo ha hecho, por ejemplo, en el asunto Pocasovschi y Mihaila v. República de Moldavia y Rusia (asunto núm. 1089/09, Sentencia de 29 de mayo de 2018), en el que advierte que, en lo que respecta a la República de Moldavia, el Tribunal observa que - como ya declaró en los asuntos Ilaşcu, Catan y Mozer-, aunque Moldavia no tiene un control efectivo sobre la región de Transnistria, es, sin embargo, el Estado en cuya jurisdicción territorial estaban las personas que habían sufrido la violación de sus derechos fundamentales, y por su obligación de garantizar los derechos y libertades definidos en el Convenio de Roma de 1950 se circunscribe a adoptar las medidas diplomáticas, económicas, judiciales y de otra índole que pueda de conformidad con el Derecho internacional; obligaciones que califica de «positivas» (párr. 44). En el citado asunto Mozer lo explica ampliamente al considerar que cuando un Estado Parte no puede ejercer su autoridad sobre la totalidad de su territorio debido a una situación de facto restrictiva, como la que se produce cuando se establece una entidad separatista en aquel, independientemente de si va acompañado o no de ocupación militar por otro Estado, no deja de tener jurisdicción, sin embargo, en el sentido del art. 1 del Convenio sobre esa parte de su territorio temporalmente sujeta a una autoridad local sostenida por fuerzas rebeldes o por otro Estado. No obstante, entiende que esa situación fáctica reduce el alcance de esa jurisdicción en la medida en que el compromiso asumido por el Estado con arreglo al art. 1 debe ser considerado por el Tribunal únicamente a la luz de las obligaciones positivas del Estado contratante respecto de las personas situadas en ese territorio, lo que implica que «debe esforzarse, con todos los medios legales y diplomáticos disponibles para con los Estados extranjeros y las organizaciones internacionales, en seguir garantizando el disfrute de los derechos y libertades definidos en la Convención» (párr. 97).

La tercera opción consiste en atribuir la responsabilidad internacional, en defecto de potencia ocupante o Estado que controle de otra forma el territorio, a una entidad no reconocida como Estado. Para ello es necesario, en primer lugar, según la jurisprudencia del TEDH, que se verifique que el Estado titular de ese territorio no lo gobierna efectivamente, lo que puede derivarse del análisis de los hechos y también de un reconocimien- 
to expreso al efecto. Esto último ha sucedido con Transnistria, puesto que Moldavia manifestó en la ratificación del Convenio de Roma, efectuada el 12 de septiembre de 1997, que «la República de Moldavia declara que no podrá garantizar el cumplimiento de las disposiciones de la Convención con respecto a las omisiones y los actos cometidos por los órganos de la autoproclamada República Transnistria dentro del territorio efectivamente controlado por dichos órganos hasta que el conflicto en la región finalmente se resuelva». En Ilaşcu y otros v. Moldavia y Rusia el TEDH constata que «la República Transnistria de Moldavia se había establecido en ese territorio y tenía sus propias instituciones, incluidas fuerzas armadas, una fuerza de policía y funcionarios de aduanas» (párrs. 300-301). A estos efectos, la cuestión que se plantea el TEDH es si la entidad secesionista puede considerarse como un movimiento insurreccional y, por tanto, aplicando las reglas generales del Derecho internacional ${ }^{40}$, atribuir la responsabilidad al Estado que surja de esa acción de ruptura del orden constitucional. A este respecto, llama la atención que reconozca a la autoridad de facto la presunción de que se convertirá en el gobierno de un Estado plenamente integrado en la comunidad internacional ${ }^{41}$. El fundamento de la particular interpretación de esta regla sobre la responsabilidad internacional es la anteriormente referida «doctrina de los derechos humanos adquiridos». El TEDH entiende que el objetivo de su actuación supervisora debe ser evitar un vacío en la protección de los derechos tutelados. En Bankovic y otros $v$. Bélgica y otros Estados contratantes (Decisión sobre la admisibilidad de 12 de diciembre de 2001) recuerda que «en su sentencia Chipre $v$. Turquía antes citada, el Tribunal era consciente de la necesidad de evitar "un vacío lamentable en el sistema de protección de los derechos humanos" en el norte de Chipre», y expresa para este caso que «en consecuencia, ante la conveniencia de evitar una brecha o vacío en la protección

40 El Proyecto de artículos sobre responsabilidad del Estado por hechos internacionalmente ilícitos de 12 de diciembre de 2001 establece en su art. 10 que: «1. Se considerará hecho del Estado según el Derecho internacional el comportamiento de un movimiento insurreccional que se convierta en el nuevo gobierno del Estado. 2. El comportamiento de un movimiento insurreccional o de otra índole que logre establecer un nuevo Estado en parte del territorio de un Estado preexistente o en un territorio sujeto a su administración se considerará hecho del nuevo Estado según el Derecho internacional. 3. El presente artículo se entenderá sin perjuicio de la atribución al Estado de todo comportamiento, cualquiera que sea su relación con el del movimiento de que se trate, que deba considerarse hecho de ese Estado en virtud de los arts. 4 a 9».

${ }^{41}$ Cfr. P. DumberRY, «New State Responsibility for Internationally Wrongful Acts by an Insurrectional Movement», European Journal of International Law, vol. 17, núm. 3 (2006), pp. 605-621. 
de los derechos humanos, hasta ahora el Tribunal se ha basado en el establecimiento de la jurisdicción solo cuando el territorio en cuestión era tal que, por las circunstancias específicas, normalmente estaría cubierto por la Convención» (párr. 80). Por ello ha reconocido que la obligación impuesta por el Consejo de Seguridad de no recocer a una entidad de facto como la RTNC no supone ignorar los actos de la misma de forma absoluta, puesto que los habitantes de ese territorio son administrados en su vida cotidiana por dicha entidad, lo que no puede ser desconocido por terceros Estados o por instituciones internacionales, como se estableció en el caso Takis Demopoulos v. Turquía (asunto núm. 46113/99 y otros, Sentencia de 1 de marzo de 2010, párr. 94) al admitir el cumplimiento del requisito del agotamiento previo de los recursos internos ante las instancias de la entidad turcochipriota, corrigiendo su criterio anterior.

\section{CONSIDERACIONES FINALES CON LA VISTA PUESTA EN CATALUÑA}

Este panorama, simplemente ejemplar y principalmente europeo, de la situación en materia de derechos humanos de las minorías resultantes en los Estados o entidades creadas mediante secesión evidencia varias circunstancias.

En primer lugar, que la motivación identitaria que fundamenta y preside los procesos secesionistas, de igual forma que fomentan el pleno respeto y ejercicio de la diferenciación de la minoría nacional movilizada al efecto, puede ser, sin embrago, la causa de la discriminación más o menos notoria y más o menos grave de las minorías resultantes en el nuevo Estado. En este concepto de minorías resultantes cabe también —además de las afines con el Estado matriz y otras diferentes, como hemos visto en el ejemplo de Etiopía y Eritrea - una población étnicamente coincidente con el nuevo Estado que, sin embargo, no ha estado movilizada para conseguir la independencia de su grupo étnico. En Cataluña esta situación es absolutamente evidente, por cuanto la mayoría de su población comparte los elementos objetivos del pueblo (basados principalmente en la lengua y la cultura), pero solo una parte de la misma está movilizada para conseguir la independencia de España. Lo que convertiría a la mitad de la población en minoría nacional resultante en un eventual Estado de Cataluña es solo esa ausencia de elemento subjetivo. Y lo más grave de esta situación es que se asemeja a la de los «rusos bálticos», aunque no por la diferenciación étnica 
o lingüística, sino por la percepción en la nueva hipotética mayoría social de su afinidad con el proyecto estatal del Estado matriz, siendo especialmente grave, en este contexto, que la Gran Sala haya corregido la jurisprudencia del TEDH en el sentido de ampliar el margen de discrecionalidad de los Estados incluso admitiendo la inelegibilidad de candidatos que se opusieron al proceso secesionista si ello supone, en su consideración, una defensa de la independencia y seguridad del nuevo Estado.

En segundo lugar, cuando la nueva mayoría de un Estado secesionado quiere asegurar la irrelevancia política de sus minorías resultantes suele recurrir a prácticas «odiosas», pero no necesariamente ilícitas según el Derecho internacional. El ordenamiento jurídico internacional no puede regular ni los organismos internacionales supervisores controlar cuestiones como la prohibición o no de partidos étnicos o religiosos, siempre que se permita la participación política de todos sus ciudadanos en igualdad de condiciones. Como tampoco se puede regular ni supervisar la configuración de los distritos electorales o de los umbrales mínimos de los votos necesarios para acceder a las cámaras parlamentarias. Pero que una situación no sea ilícita no impide que los nuevos Estados responsables de esos comportamientos «odiosos» no puedan ser excluidos de las organizaciones regionales fundamentadas en una auténtica democracia parlamentaria. Si la OSCE, el Consejo de Europa y la UE han presionado a países como Macedonia para que enmienden estas situaciones de gerrymandering, también podrían influir en otros países, como los bálticos o algunos exyugoslavos, para adoptar umbrales electorales más favorables para los partidos que representan a sus minorías o para evitar esas manipulaciones de las circunscripciones electorales. Incluso, sería más conveniente que el Consejo de Europa regulara con mayor precisión algunos aspectos del «principio democrático», si no en la forma de reglas iguales para todos los Estados, que parece inviable, sí al menos en la forma de conductas prohibidas, como la delimitación de circunscripciones electorales con diferencias que superen un porcentaje de población entre ellas (15 por 100, por ejemplo) o el establecimiento de umbrales mínimos electorales ad hoc (estableciendo un mínimo común, por ejemplo, el 3 por 100). De lo contrario, en nuestro caso, en una hipotética República de Cataluña podríamos ver que, para el mismo número de representantes parlamentarios, las comarcas con mayor presencia nacionalista tuvieran menos electores censados que las zonas de asentamiento de la población no nacionalista, al estilo de los distritos albaneses en Macedonia.

En tercer lugar, los obstáculos o impedimentos para acceder a la nacionalidad que se establecen en países como Estonia o Letonia basados en 
el conocimiento del idioma nacional por su carácter sobrevenido, esto es, despojando a quienes la tenían de la nacionalidad propia del territorio en el que viven, contradice lo dispuesto en el art. 15 de la Declaración Universal de los Derechos del Hombre de 1948 — por tratarse de una sustracción arbitraria de la nacionalidad - y en el art. 1 del Convenio de las Naciones Unidas para la reducción de la apatridia de 1961, según el cual «todo Estado contratante concederá su nacionalidad a la persona nacida en su territorio que de otro modo sería apátrida». Indudablemente, no se puede obligar a los Estados a participar en este tratado internacional, pero el Consejo de Europa sí puede exigir a sus miembros que aseguren la vigencia de determinados derechos fundamentales y, por tanto, promover de forma más eficaz la participación en la Convención Europea sobre la Nacionalidad de 1997 y en el Convenio sobre Prevención de los Casos de Apatridia con relación a la Sucesión de Estados de 2006. Se ha criticado, con razón, el poco consistente condicionamiento puesto en esta materia a los nuevos Estados que se han incorporado en las últimas décadas tanto al Consejo de Europa como a la UE ${ }^{42}$. Lo mismo puede decirse de la situación de discriminación laboral por desconocimiento suficiente del idioma nacional. Trasladada la situación a una futurible estatalidad catalana, podríamos encontrarnos, en primer lugar, con catalanes (étnicos) a los que no se les permita adquirir la nacionalidad catalana por residir en Galicia o en Andalucía y ser sospechosos de poca afección al nuevo Estado, como en el caso de los «eritreos etíopes», lo cual no es muy disparatado si se tiene en cuenta que la Ley 9/2017, de 6 de septiembre, de Referéndum de Autodeterminación, aprobada por el Parlamento de Cataluña, en el art. 6 incluye entre las personas que tienen derecho al voto en esa consulta los catalanes residentes en el extranjero en determinadas condiciones de residencia y solicitud, pero no los residentes en el resto del territorio de España ${ }^{43}$.

Y, en cuarto lugar, no ofrece mucha seguridad jurídica que ante la ausencia de normas convencionales en las que sean parte la generalidad de

42 Vid. B. ARP, Las minorías nacionales..., op. cit., pp. 388 y 393.

${ }^{43}$ Art. 6.1: «Són cridades a votar en el referèndum les persones que tenen dret de vot en les eleccions al Parlament de Catalunya. També tenen dret de vot els catalans residents a l'estranger que hagin tingut el darrer veïnatge administratiu a Catalunya, que donin compliment als requisits legalment exigibles $i$ que hagin sol-licitat formalment de prendre part en la votació». Disposición que es contradictoria con lo previsto en el art. 7.2.b) de la Ley 20/2017, de 8 de septiembre, de Transitoriedad Jurídica y Fundacional de la República, puesto que para la solicitud de la nacionalidad no distingue cuando incluye a los que residan fuera de Cataluña y hayan tenido su última residencia administrativa en un municipio de Cataluña al menos durante cinco años. 
los Estados, las reglas que establezcan la continuidad de las normas sobre derechos humanos en un cambio de titularidad territorial por secesión sean exclusivamente establecidas por una interpretación de los organismos internacionales supervisores, ya sea el Comité de Derechos Humanos de la ONU, la Corte Interamericana de Derechos Humanos o el Tribunal Europeo de Derechos Humanos. Puesto que en el sistema regional europeo la jurisdicción del Tribunal de Estrasburgo es obligatoria para los Estados miembros del Consejo de Europa y su doctrina es uniforme sobre la continuidad en esta materia, incluso con reglas especiales para los casos de entidades de facto, debería establecerse convencionalmente y ser una condición para la pertenencia a esta organización, pues no puede haber espacios sin protección en este ámbito que es esencial axiológicamente para esta organización internacional. Tanto la Ley de Transitoriedad Catalana como la de Referéndum, declaradas inconstitucionales por nuestro Alto Tribunal, establecen en su art. 15 la «continuidad de los tratados internacionales»; sin embargo, cuando hace referencia a los relativos a los derechos humanos en su art. 22.2 no incluye ni el Convenio Marco sobre Protección de las Minorías Nacionales de 1995 ni la Carta Europea de las Lenguas Minoritarias de 1992.

Lo más preocupante de esta práctica internacional es que se aprecia la existencia de un patrón común, salvo honrosas excepciones, y especialmente en los primeros años siguientes a la independencia, de no reconocimiento de la diferenciación de las minorías resultantes en los Estados o entidades secesionadas, en algunos casos muy graves también de exclusión del nuevo Estado, particularmente dificultando el acceso a la nacionalidad, cuando no al trabajo, y en otros de reducción a la marginalidad política manipulando interesadamente parámetros electorales. Los mecanismos de reconducción de estas situaciones anómalas —especialmente en un contexto europeo con una triple supervisión de los derechos humanos a cargo a nivel regional del Consejo de Europa, la OSCE y la UE— han sido muy lentos (como demuestran los ejemplos de Letonia o de Macedonia) o incluso no del todo eficaces (como en Estonia). Curiosamente, su eficacia es mayor y más rápida en los territorios administrados por entidades no reconocidas, gracias a una suerte de ingeniería jurídica como la realizada por el TEDH y, obviamente, al interés de estas entidades de homologarse internacionalmente. El art. 2 del Tratado de la Unión Europea prescribe que «la Unión se fundamenta en los valores de respeto de la dignidad humana, libertad, democracia, igualdad, Estado de Derecho y respeto de los derechos humanos, incluidos los derechos de las personas pertenecien- 
tes a minorías. Estos valores son comunes a los Estados miembros en una sociedad caracterizada por el pluralismo, la no discriminación, la tolerancia, la justicia, la solidaridad y la igualdad entre mujeres y hombres». En Europa los ejemplos bálticos y balcánicos han mostrado las fisuras del sistema de protección de los derechos humanos. La posibilidad de que nuevos ciudadanos europeos puedan verse privados de sus derechos fundamentales por una eventual secesión, quién sabe si en el Ulster, Flandes o Cataluña, debería mover a los países realmente democráticos y respetuosos del Estado de Derecho a modificar y generalizar nuestras normas convencionales al respecto y a exigir su efectividad para ingresar en nuestras organizaciones regionales.

\section{BIBLIOGRAFÍA}

Aasland, A., «Citizenship Status and Social Exclusion in Estonia and Latvia», Journal of Baltic Studies, vol. 33, núm. 1 (2007), pp. 57-77.

Andaluz Vegacenteno, H., «El derecho de la sucesión de Estados», Revista de la Facultad de Ciencias Sociales y Jurídicas de Elche, vol. I, núm. 2 (2007), pp. 258-293.

ARP, B., Las minorías nacionales y su protección en Europa, Madrid, CEC, 2008.

Aust, A., Convención de Viena sobre la sucesión de Estados en materia de tratados, New York, United Nations, 2010.

Cassese, A., Self-Determination of Peoples: A Legal Reppraisal, New York, Cambridge University Press, 1995.

CRAWFORD, J., The Creation of States in International Law, New York, Oxford University Press, 1997.

Díaz BARRADO, C., La protección de las minorías nacionales en el Consejo de Europa, Madrid, Edisofer, 1999.

Dorodnova, J., «¿Quién pertenece a Letonia?», Tempo Exterior, núm. 5 (2002), pp. 33-53.

- «Challenging Ethnic Democracy: Implementation of the Recommendations of the OSCE High Commissioner on National Minorities to Latvia, 1993-2001», CORE Working Paper, núm. 9 (2003).

DRNAS DE ClÉMENT, Z., «La complejidad del principio pro homine», Jurisprudencia Argentina, núm. 12 (2015), pp. 98-111.

DumberRY, P., «New State Responsibility for Internationally Wrongful Acts by an Insurrectional Movement», European Journal of International Law, vol. 17, núm. 3 (2006), pp. 605-621.

FloRes Juberías, C., «Sistemas electorales y minorías étnicas en la Europa Central y del Este: de la transición a la consolidación de la democracia», Revista de Estudios Políticos, núm. 166 (2014), pp. 41-67. 
Freixes Sanjuán, T., «Secesión de Estados e integración en la Unión Europea. A propósito del debate sobre la permanencia en la Unión de Escocia y Cataluña como Estados segregados del Reino Unido y España», Revista Jurídica de Catalunya, núm. 2 (2014), pp. 297-329.

Galbreath, D., «The Politics of European Integration and Minority Rights in Estonia and Latvia», Perspectives on European Politics and Society, vol. 4, núm. 1 (2008), pp. 35-53.

García Andrade, P., «La ciudadanía europea y la sucesión de Estados: a vueltas con las implicaciones de una separación territorial en el seno de la UE», Revista de Derecho Comunitario Europeo, núm. 49 (2014), pp. 997-1025.

García-Corrochano Moyano, L., «Sucesión de Estados en materia de tratados», Agenda Internacional, vol. 3, núm. 7 (1997), pp. 121-132.

Gros Espiell, H., «Los métodos de interpretación utilizados por la Corte Interamericana de Derechos Humanos en su jurisprudencia contenciosa», en R. Nieto Navia (ed.), La Corte y el sistema interamericano de derechos bumanos, San José de Costa Rica, CIDH, 1994, pp. 39 y ss.

JÄRVE, P., «Ethnic Democracy and Estonia: Application of Smooha's Model», European Centre for Minority Issues Working Paper, núm. 7 (2000).

Kaminga, M. T., «State Succession in Respect of Human Rights Treaties», European Journal of International Law, vol. 7, núm. 4 (1996), pp. 469-484.

López Martín, A. G., y Perea Unceta, J. A., Creación de Estados, secesión y reconocimiento, Valencia, Tirant Lo Blanch, 2018.

Mariño MenÉndeZ, F., La protección internacional de las minorías, Madrid, Ministerio de Asuntos Sociales, 2001.

Martínez Jiménez, A., El derecho de autodeterminación de los pueblos en el siglo XXI, Pamplona, Aranzadi, 2015.

Medina Ortega, M., «Los ciudadanos europeos y la secesión de territorios en la Unión Europea», Revista de Derecho de la Unión Europea, núm. 25 (2013), pp. 69-86.

Musgrave, Th. D., Self-Determination and National Minorities, New York, Oxford University Press, 2000.

Odriozola Mariscal, C. E., «Tratados y sucesión de Estados», Ars Iuris, núm. 22 (1999), pp. 184-216.

Pascual Vives, F. J., «Consenso e interpretación evolutiva de los tratados regionales de derechos humanos», Revista Española de Derecho Internacional, vol. 66, núm. 2 (2014), pp. 113-153.

Perea Unceta, J. A., El Derecho internacional de secesión, Madrid, Facultad de Derecho de la Universidad Complutense de Madrid, 2008.

Pons Rafols, X., Cataluña: derecho a decidir y Derecho internacional, Madrid, Reus, 2015.

Radoslavov Yordanov, Y., «La secesión de territorios en un Estado miembro de la Unión Europea y sus consecuencias en relación con las minorías resul- 
tantes», Anuario Hispano-Luso-Americano de Derecho Internacional, núm. 23 (2017), pp. 385-422.

Ridao Martín, J., y GonzÁlez Bondía, A., «La Unión Europea ante la eventual creación de nuevos Estados surgidos de la secesión de Estados miembros», Revista de Derecho de la Unión Europea, núm. 28 (2014), pp. 363-390.

RuIz VieYTez, E., Minorias, inmigración y democracia en Europa. Una lectura multicultural de los derechos bumanos, Valencia, Tirant lo Blanch, 2006.

Schachter, O., «State Succession: The Once and Future Law», Virginia Journal of International Law, vol. 33 (1993), pp. 253 y ss.

Smith, G., «The Ethnic Democracy Thesis and the Citizenship Question in Estonia and Latvia», Nationalities Papers, vol. 24, núm. 2 (2007), pp. 199-216.

TANCREDI, A., La secesione nel diritto internationale, Padova, Cedam, 2006.

TRINDADE, A. A. C., Direito internacional e direito interno: sua interação na proteção dos direitos bumanos, San José de Costa Rica, 2004. 